\section{REITER'S DISEASE}

\section{BY}

\section{R. BAXTER, M.B., Ch.B., M.R.C.P. \\ Physician, Hillingdon County Hospital}

The recent article by Jackson and the case report by Wrigley on the syndrome known as Reiter's disease (B.M.J., 1946, 2, $197,199)$ will no doubt have stimulated clinicians to review in retrospect a number of hitherto obscure cases. It will be remembered that the disease is characterized by the triad of non-specific urethritis, arthritis, and conjunctivitis, with the occasional acconıpaniment of keratodermia blennorrhagica, haematuria, and diarrhoea.

A. M. H. Gray in his article on keratodermia blennorrhagica (Med. Annu., 1941) quotes Epstein as associating this disease with inflammation of the joints and eyes and discussing its relation to psoriatic arthritis, believing the two conditions to be distinct; for, whereas psoriasis more usually appears on knees and elbows and sometimes on trunk and extremities, the lesions of keratodermia are entirely confined to soles and palms. This view, he goes on to point out, is further confirmed by Taylor, who describes the condition as one secondary to severe polyarthritis and posterior urethritis of gonococcal origin. Gray further quotes Combes, Dietrich, and Cohen, who, after minutely describing the skin lesions, point out that the arthritis is not of the more usual monarticular variety seen in gonococcal infections but a polyarthritis which involves chiefly knees, ankles, wrists, and acromio-clavicular joints, and which, further, shows less than the usual periarticular oedema and inflammation.

Reports of cases of Reiter's disease are so few that the occurrence of a case which in retrospect fits closely into the clinical picture would appear to justify its publication.

\section{Case Report}

The patient was an English soldier of 41 who was admitted to Hillingdon County Hospital on Dec. 12, 1945, with the following history. Until the beginning of August, 1945, he had been in perfect health and had not-and in this he is to be believed-run the risk of venereal infection. About Aug. 1, while serving in Norway, he developed an acute conjunctivitis, which became purulent within a short time and for which he received local treatment. He was repatriated on Sept. 6 and admitted to another hospital, where the conjunctivitis, still acute, was treated with peniciilin drops. A few days after his admission an acute purulent urethral discharge made its appearance; he had never had such a thing before. Repeated examinations of the discharge failed to reveal the presence of gonococci, and serological examinations were likewise negative. Parenteral penicillin resulted in complete disappearance of the discharge in five days; nor was there any recurrence. Three months after the onset of the conjunctivitis the patient developed an intraocular haemorrhage in the right eye, and a few days later iritis in the same eye. The iritis ran its usual course of ten to twelve weeks, and settled down only to recur after his admission to this hospital, as will be described later.

Four months after the original conjunctivitis joint symptoms were first complained of, the ankles, knees, and shoulders becoming stiff but exhibiting no signs of redness or sweiling. Not until two weeks later was the first sign of swclling noted-in the second left metacarpo-phalangeal joint-and the temperature for the first ime was found to be above normal. At approximately the same time that joint symptoms first became manifest a scaly eruption of the soles was observed.

On Dec. 12 the patient was admitted to this hospital, and his condition was then as follows. He was somewhat thin, and arms and legs showed wasting consistent with a prolonged stay in bed from subacute arthritis. The ankles were swolien and painful and only slightly red; the knees were stiff and painful but not swollen; the left shoulder and elbow were in a similar condition, and the only other affected joint-the second left metacarpo-phalangeal-was swollen, slightly red, and very painful. There was a thick scaly eruption of both soles, which was misdiagnosed as psoriasis in spite of the absence of other skin lesions, and under the free edges of the nails of some of the fingers was a collection of dry cheesy material. The conjunctivae were slightly inflamed, but there was no crusting of the lids. The right eye showed signs of old iritis, with a fixed irregular pupil and posterior synechiae. There was no urethral discharge and the urine was normal. Examination of the other systems was negative, but the E.S.R. was 106 , and the gonococcal complement-fixation test and Wassermann reaction were both negative. The temperature on admission was normal.
A course of "myocrisine" was started on Dec. 31, to which the response was satisfactory in that, the day after each injection, increased pain was experienced in the affected joints, and a slow but steady improvement in mobility and pain took place so that two months later the patient was once more able to walk. Since then there has been no relapse, and on Sept. 13, 1946, the only sign of trouble is a persistence of some swelling and stiffness of the metacarpo-phalangeal joint.

A recurrence of iritis of the right eye took place on Jan. 31, 1946, resolving in the course of ten weeks with the help of hot bathing and instiliations of atropine, "protargol," and other eye drops. On May 8 the left eye devcloped iritis, which resolved in about eight weeks. At the time of the last examination, on Sept. 13, there was no sign of inflammation in either eye, although synechiae persisted.

The scaly eruption of the soles continued pari passu with the joint lesions, and at one time it caused considerabie distress from the foul odour arising from the layers of dead skin. Treatment with Condy's-fluid baths and the use of a detergent ointment resulted in some improvement, but as the joints cleared so did the skin, and now there is no trace of it on the soles; under three nails on the hands there is a small collection of dry cheesy material.

During the first twelve weeks after admission he ran a slight rregular temperature-never above $98.8^{\circ} \mathrm{F} .\left(37.1^{\circ} \mathrm{C}\right.$.).

The patient has recently been readmitted to have an operation for hammer toe, and, apart from the few signs mentioned above, he now shows no trace of the illness which started just over a year ago. Weight and colour have returned, and he looks forward to being able to restart work soon.

\section{Comment}

The interest in this case lies in the exhibition of all the symptoms of the disease except for the diarrhoea and haematuria, as well as in the sequence in which the symptoms made their appearance-conjunctivitis, urethritis, then polyarthritis and keratodermia coincidently, with recurrent iritis as a concomitant. In view of the complete clearance of symptoms and signs as reported in other cases, it is doubtful if the treatment given in this case had any effect if we except only the rapid clearance of the urethral discharge with penicillin.

I have to thank Dr. W. Arklay Steel, medical director of Hillingdon County Hospital, for permission to publish this report.

\section{Medical Memoranda}

\section{Perineal Suture in Obstetric Practice}

In my practice the patient is generally delivered lying in the left lateral position, even when delivery is instrumental, as it is easier when one is single-handed. In this position, satisfactory as it is for the delivery, visualization and suture of a perineal laceration are difficult, since the raw edges tend to fall together and it is far from easy to locate the upper end of the vaginal part of the tear. In an attempt to solve this difficulty the method described below has been evolved. The basis of the technique is insertion of two deep tension silkworm-gut sutures placed longitudinally on each side of the perineum before delivery of the child. The inseriion of these sutures is made near the end of the second stage in such cases as (1) where perineal laceration may be expected; (2) where episiotomy is necessary; and (3) where there is marked stretching of the perineum.

\section{TECHNIQUE}

Two semi-curved Hagedorn needles are threaded with strong silkworm gut. The area round the perineum is thoroughly sterilized by washing the part with biniodide solution. The index and middle fingers of the left hand are inserted into the lower third of the vagina, and then separated in fanlike manner in order to protect the presenting part and also to draw the perineum forwards. The needle is inserted through the perineal skin about $1 / 4$ in. $(6 \mathrm{~mm}$.) from the midinc and $1 / 4$ in. from the muco-cutaneous junction, the point passing deeply into and through the vaginal mucosa. The needle then travels within the vaginal cavity, re-entering the deep tissues 2 in. $(5 \mathrm{~cm}$.) nearer the vaginal vault and emerging through the perineal skin $1 / 2$ in. $(1.25 \mathrm{~cm}$ ) above and lateral to the anus. Within the vagina the suture lies on the mucous membrane and the lower end traverses the muscles surrounding the anus. The suture is repeated on the other side of the porineum. and both stitches are secured by clamping the free ends of the silkworm gut with artery forceps. With these stitches in position the delivery of the child is completed. Should a laceration have taken piace or an episiotomy been necessary the inspection of the wound and the estimation of its extent can easily be carried out by traction on the two lateral 
sutures. Access to the depth of the wound is made easy, and the insertion of catgut su:ures for the repair of the vaginal mucosa and deep muscles made relatively accurate. After the catgut sutures have been inserted and tied the skin is closed by tying the free ends of the silkworm sutures.

\section{COMMENTARY}

The value of this technique lies in the fact that (1) it renders the single-handed repair of an episiotomy or laceration moderately easy ; (2) the sutures are in place should laceration occur; (3) if there has been no laceration or episiotomy, but considerable stretching of the parts has caused injury to the deeper tissues, these separated deep tissues are held together by the sutures.

I am aware that self-retaining retractors have been devised to facilitate perineal repair. These are more satisfactory when stitching is done with the patient in the dorsal position, but their use also implies introduction of instruments into a fresh wound in that area.

Broomhill, Selkirk.

D. Charteris Graham, M.B., Ch.B.

\section{Transverse Rupture of External Auditory Meatus}

Recent reports in these columns of minor but interesting and unusual injuries prompt me to record a case of traumatic transverse rupture of the external auditory meatus. I have not previously heard or read of this injury. In the present case the nature of the causal trauma was no doubt a shearing force transverse to the line of the meatus.

\section{Case History}

A girl aged 9 was knocked down by a motor car. In the casualty department a small and superficial cut behind the right auricle was cleansed and sutured, and the patient was admitted to the ward for observation in case of intracranial injury. No evidence of serious injury was found, however, but blood was seen to be escaping from the right auditory meatus. Examination with the auriscope revealed a complete annular laceration of the skin tube at a depth of $5 \mathrm{~mm}$. from the bottom of the concha. The inner part of the meatus had retracted and was visible only as a small circular skin edge, round which lay the damaged supporting cartilage. Repair was undertaken under general anaesthesia. The cut behind the auricle was reopened, excised, and extended, and then deepened anteriorly so as to expose the divided ends of the meatus (see Fig. A). After excision of ali tags of tissue, including loose pieces of cartilage, the ends of the skin-cartilage tube were found to fit neatly together and were sutured with five fine catgut stitches, passing through skin and subcutaneous tissue (Fig. B). Sulphanilamide powder was
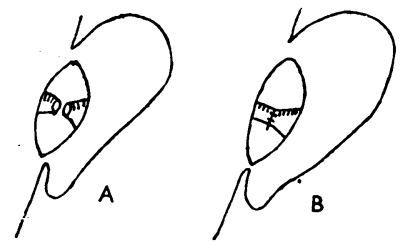

Showing the external meatus (A) before and (B) after repair.

inserted, and the retro-auricular wound closed with a small rubber dam drain through its lower end. A flavine-in-glycerin pack was inserted into the now continuous meatus. Healing took place rapidly and without sepsis, and a slight tendency to stenosis was subsequently treated by repeated dilatation.

DouglaS R. K. REID, M.D., F.R.C.S.,
Dunedin Hospital, New Zealand.

\section{A Case of Reiter's Disease}

Practically all the articles on Reiter's disease during the past three years have appeared in American or Canadian medical journals. I understand from colleagues that cases with symptoms that correspond to the recognized syndrome of polyarthritis, urethritis, and conjunctivitis are not rare in this country, especially in V.D. departments, but as very few cases have been recorded the following typical case may be of interest. As an allergic reaction to bacillary dysentery may be the cause in some cases (Reiter's original case was associated with diarrhoea and blood in the stools), it is interesting to note that this patient had not had diarrhoea in the year preceding the onset of his illness, during which time he had been in this country.

The patient, an Englishman aged 34, served in various parts of the Middie East from November. 1940, to January, 1945. when he returned home. He had three mild attacks of diarrhoea during that time, the last in 1944 . No attack lasted more than three days, there was no blood in the stools, and he was not admitted to hospital. He believes he had conjunctivitis in both eyes in December, 1944 which persisted for about two weeks. A dental abscess developed in December, 1945, and a tooth was removed on Feb. 5, 1946. In January, 1946, he experienced pain in the left side of the back, and a week later there was a slight urethral discharge, but no dysuria or frequency. The following day he had conjunctivitis of both eyes. Two urethral smears showed many pus cells and some mixed organisms, but no epithelial cells or Neisserian organisms. He denied any chance of exposure to venereal infection before the onset of his illness. Non-gonococcal urethritis was diagnosed, and a course of sulphathiazole ( $27 \mathrm{~g}$. in ali) was given. Ten days after the onset of the urethral discharge his right ankle became swollen, and a few hours later there was swelling and pain in the left knee. Next his back became stiff, and pain and stiffness in the shoulders, elbows, and fingers began; none of these latter joints became swollen. He was admitied to hospital on Feb. 9, two weeks after the onset of the urethrai discharge.

On examination he was seen to be a well-developed adult male. He had severe bilateral purulent conjunctivitis. There was some pain and stiffness in the lumbar region on movement. The light ankle was red, hot, and swollen. There was some limitation of flexion of the right knee but no swelling. Movements of the armjoints were full, but he couid not flex the fingers of the right hand owing to pain. His oral temperature was $101^{\circ} \mathrm{F}$. $\left(38.3^{\circ} \mathrm{C}\right)$, pulse rate 100 , and respirations were below 20 ; his pulse was reguiar. The blood pressure was $130 / 85$. The throat was clean, and the teeth showed no obvious sepsis. There were no abnormally enlarged glands and no sign of abnormality in the chest or abdomen. Smears from the eye swabs showed a few polymorph pus cells but no organisms, and cuitures were sterile. The blood count showed: haemoglobin, 14.8 g. \% ; R.B.C., 4,640,000; W.B.C., 6,800 (polymorphs $66 \%$, lymphocytes $34 \%$ ). He was given sod.' sal. and sod. bicarb., $\bar{a} \bar{a}, 30$ gr. ( 2 g.) four-hourly, and the eyes were treated with irrigations and atropine instillations. On Feb. 11 the B.S.R. was 75 $\mathrm{mm}$. per hour. The urine contained a fair amount of pus: a stained deposit showed a few Gram-positive diplococci. He continued to run a mild pyrexia of 99 to $100^{\circ} \mathrm{F}$. $\left(37.2-37.8^{\circ} \mathrm{C}\right.$.). On Feb. 22 the prostatic smear was crowded with polymorph and epithelial cells. Only a vcry few staphylococci were seen in the fresh smears. The urethral discharge was very scanty by this time. Next day he was given 200,000 uni:s of penicilin in beeswax and peanut oil. $\mathrm{He}$ had no further urethral discharge after this. During the next two days there was a definite improvement in the eye condition, but the temperature and joint pains remained unaltered. Sodium salicylate was stopped on Feb. 28. On March 1 the B.S.R. was $74 \mathrm{~mm}$. per hour.

The temperature had not settled by March 9, and he was still getting pains in the left lower back and across the shoulders and some pain and stiffness in the legs. Penicillin, 30,000 units intramuscularly, was given, followed by 15,000 units three-houriy. This was continued for six days, when a total of 645,000 units had been given. The temperature was not affected and the pulse rate remained at between 80 and 100 . On March 13 the blood showed $\mathrm{Hb}$, 13.3 g. \% ; R.B.C., 3,720,000; W.B.C., 8,100 (polymorphs 66\%, lymphocytes $29 \%$, monocytes $4 \%$, eosinophils $1 \%$ ). Mist. ferri ammon. cit. was given and he was sent to a convalescent home on the 15 th to remain in bed there. The temperature became more "settled about the end of March, and early in April it was mainly normal, with occasional rises to $99^{\circ} \mathrm{F} .\left(37.2^{\circ} \mathrm{C}\right.$ ). The puise was steady, between 80 and 90 . While at the convalescent home he had toothache.

The patient returned to hospital on April 15 complaining of pain in the right shoulder, down the right arm, and in the right ankle. He still had conjunctival iniection after sleeping. His blood count now was: Hb, 16.3 g. \%; R.B.C., 5.200,000: W.B.C., 7,500. Wassermann. Kahn, and gonococcal complement-fixation tests were negative. B.S.R. $36 \mathrm{~mm}$. Urine: pus cells two per field, no organisms seen. Examination showed slight iniection of the left coniunctiva. Right ankic: full movemen's, but skin reddened over the outer part. He still complained of pain in the right ankle, but skiagrams revealed nothing abnormal. On A pril 22 he complained of some tenderness in the left ankle and slight puffiness. He still had toothache, and a skiagram on the 26th showed some bone infection near the root of $-\left.\right|^{\frac{34}{4}}$. On May $2 \frac{2-\mid \frac{3}{25} 7}{2}$ were extracted under gas. B.S.R. $30 \mathrm{~mm}$.

On June 9, four months after admission, he was feeling better, but still had occasional joint pains and slight coniunctival injection in the morning. B.S.R. $9 \mathrm{~mm}$. Urine: no albumin, no pus, blood, or casts, no organisms seen. He started to get up, and sulphacetamide ointment was applied locally to the eyes, without improvement. He was discharged from hosnital on June 28 . The temperature was normal, rising very occasionally to $99^{\circ} \mathrm{F}$. $\left(37.2^{\circ} \mathrm{C}\right.$.), the pulse rate between 70 and 90 , and the B.S.R. $8 \mathrm{~mm}$.

$\mathrm{He}$ was seen on three occasions as an out-patient, the last time on Oct. 26-nine months after the onset of his illness. He still had some mild aching in the joints, especially of the right arm and right ankle, and also occasional pains in the lumbar region and the back of the neck, which varied with the weather. A skiagram of the right ankle showed no evidence of structural change in the joint. He had no urinary symptoms. but was still getting slight injection of the eyes on waking. B.S.R. was $8 \mathrm{~mm}$. per hour.

I wish to thank $\mathrm{Dr}$. Ronald McD. Cairns, who was in charge of the case, and at whose suggestion $I$ have written it up, for permission to publish this report.

Duncan Forbes, M.B., Ch.B., Recident Medical Officer.
Leicester Royal Infirmary. 